\title{
Editorial
}

Eduardo Garcia Garcia'

José Marçal Jackson Filho²

\section{Sobre o projeto de reestruturação da RBSO}

Concerning RBSO re-structuring project
${ }^{1}$ Editor executivo

${ }^{2}$ Editor científico
A Revista Brasileira de Saúde Ocupacional encontra-se na fase de implantação de seu projeto de reestruturação, que busca o funcionamento autônomo e perene da revista e a melhoria da sua qualidade editorial. Alguns princípios e critérios fundamentam essa concepção de funcionamento da RBSO.

O primeiro é o princípio de liberdade editorial ou, em inglês, Editorial Freedom, definido pelo Comitê Internacional de Editores de Periódicos Médicos como ferramenta para se evitar interferências "na avaliação, seleção ou edição de artigos diretamente ou através da criação de ambiente que influencie fortemente a decisão dos editores responsáveis, que devem possuir total autoridade sobre o conteúdo editorial da revista científica”. Em consonância, o conselho editorial independente pode ter papel fundamental como colaborador no estabelecimento e na manutenção da política editorial adotada (ICMJE. International Commitee of Medical Journal Editors. Uniform requirements to manuscripts submitted to Biomedical Journals: writing and editing for biomedical publication, 2006. Disponível em: www.icmje.org. Acesso em: 06 mar 2006).

O segundo princípio fundamental é o de funcionar enquanto serviço público de qualidade. Nesse sentido, o funcionamento deve dar ênfase ao mérito científico dos artigos publicados e à relevância dos mesmos para a sociedade, assim como no oferecimento de acesso livre, fácil e permanente ao conteúdo da revista por meio de várias formas de mídia.

Nesse contexto, alguns objetivos específicos e metas foram explicitados, entre eles:

- Redesenhar o trabalho editorial, fundamentado em caráter coletivo;

- Reconceber as atribuições do Conselho Editorial e de seus membros;

- Reorganizar e fortalecer as estruturas administrativas;

- Introduzir ferramentas, em especial de informática, para agilizar o processo editorial;

- Dispor as informações sobre a revista e os conteúdos dos números publicados em site próprio.

O novo Conselho Editorial foi empossado em maio de 2007: são 14 pesquisadores de distintas áreas relacionadas à SST, provenientes de 10 universidades e instituições de pesquisa de diferentes regiões do país. As contribuições do novo Conselho foram de fundamental importância na reconfiguração de metas, estratégias e, sobretudo, da política editorial da revista.

Equipou-se a secretaria executiva da RBSO com a infra-estrutura básica necessária para oferecer o suporte operacional e coordenar o andamento da revista, desde o recebimento dos manuscritos ao acompanhamento do processo de avaliação por pares (peer-review) e de editoração dos artigos aprovados, este executado pela equipe da Divisão de Publicações da Fundacentro. 
Também foi reorganizada a distribuição da revista impressa: levantou-se e definiu-se uma relação de cerca de 500 entidades, sobretudo bibliotecas e órgãos públicos atuantes na área, que passaram a receber regularmente a publicação. A execução dessa distribuição é realizada pela Coordenação de Documentação e Biblioteca da Fundacentro.

Foi criado pela Divisão de Informática da Fundacentro um site específico para a RBSO, cujo conteúdo é mantido pela equipe editorial e pela secretaria executiva da revista. As páginas contêm as informações essenciais sobre o periódico, incluindo as normas para publicação e, sobretudo, propiciam a divulgação ágil e o acesso livre aos últimos números publicados. Há nove edições completas para downloads e, a partir do número 114, também se passou a oferecer acesso eletrônico aos artigos separadamente. Isso permitiu o aumento da visibilidade e do acesso ao conteúdo da revista concomitantemente à redução da tiragem impressa, com a conseqüente economia de recursos.

Está prevista ainda, para futuro próximo, a implantação de um sistema eletrônico para acompanhamento do processo editorial, compreendendo a submissão de manuscritos, a avaliação por pares e todo o processo de editoração até a publicação on line dos artigos. Estudos de viabilidade de aproveitamento de plataformas informatizadas de domínio público estão sendo realizados.

Os resultados de todo esse trabalho começam a ser observados. Um dos principais indicadores disso é o número de acessos e downloads que estão sendo realizados por meio do site da RBSO:

Segundo controle efetuado pela Coordenação de Documentação e Biblioteca, desde maio, quando foi criado o portal da RBSO, a dezembro de 2007, foram realizados cerca de 24.000 downloads de revistas e artigos dos últimos números ali disponíveis: uma média de 3.000 mensais.

Além desse indicador interno, há indicadores externos importantes a considerar. Um deles se refere às indexações da RBSO, que foi reindexada em três bases bibliográficas internacionais.

Outro indicador relevante é a classificação Qualis de periódicos científicos, realizada pela CAPES. A revista, que é considerada multidisciplinar, galgou Qualis “B” em três áreas e Qualis "A” - Nacional - em outras duas. Com as classificações "A" e "B" foi possível pleitear e obter o ingresso da RBSO no Portal de Periódicos da CAPES. Com isso, o periódico certamente ganhará mais visibilidade e confiabilidade, atraindo artigos de melhor qualidade.

Outra inovação recente da revista são os seminários de 'conversa com o leitor', organizados por ocasião do lançamento de cada novo número, quando autores convidados de artigos publicados apresentam seus trabalhos e têm a oportunidade de discuti-los com o público interessado no tema.

É preciso ressaltar que os avanços recentes aqui relatados só puderam ser obtidos pelo compromisso e pelo trabalho de todos aqueles direta e indiretamente envolvidos, colaboradores internos e externos, e pelo apoio oferecido pela direção da Fundacentro desde o início da proposição do processo de fortalecimento da RBSO.

Certamente ainda há muito por fazer e aprimorar para garantir a continuidade e a melhoria da RBSO. Lançada em 1973, foram 116 números, publicando cerca de 900 artigos. A reunião dessa extensa bibliografia, por si só, já mostraria a importância da revista como fonte de informação. Esse acervo, porém, tem um valor ainda maior, porque reflete toda a evolução do conhecimento ocorrida na área nesses 35 anos.

A Revista Brasileira de Saúde Ocupacional é um patrimônio da Fundacentro e da comunidade que tem interfaces com o tema da Saúde e Segurança no Trabalho. 